\title{
Brazilian symposium of theoretical chemistry (SBQT2013)
}

\author{
Itamar Borges $\mathrm{Jr}^{1} \cdot$ Marco Antonio Chaer Nascimento ${ }^{2}$
}

Published online: 10 April 2015

(C) Springer-Verlag Berlin Heidelberg 2015

This Topical Issue of the Journal of Molecular Modeling collects 23 selected works presented at the 17th Biannual Brazilian Symposium of Theoretical Chemistry (SBQT) held at the paradisiac Villa Gallé Resort Hotel nestled on the Costa Verde (Green Coast) of the State of Rio de Janeiro, Brazil, from November 24 to 28, 2013.

Following the tradition established in 1991, during the 6th SBQT and without interruption since then, selected papers presented at the Symposia, after rigorous peer-review, are published in special issues of important international scientific journals of the field. For the first time and in the same spirit, the Proceedings of 17th SBQT will be published as a Topical Issue of the Journal of Molecular Modeling. This Topical Issue is a testimony to the maturity of the Brazilian Theoretical Chemistry Community and to the major scientific meeting of the area in Latin America.

The 17th SBQT gathered over 295 participants from Brazil and abroad. The Program consisted of oral presentations from 13 foreign scientists and 17 Brazilians, 16 short talks (15 min) presented by young researchers, two posters sections, and a two-hour workshop on a new database. Without parallel sec-

This paper belongs to Topical Collection Brazilian Symposium of Theoretical Chemistry (SBQT2013)

Marco Antonio Chaer Nascimento

chaer01@gmail.com

Itamar Borges, Jr

itamar@ime.eb.br

1 Departamento de Química, Instituto Militar de Engenharia, Praça General Tibúrcio 80, Rio de Janeiro, RJ 22290-270, Brazil

2 Departamento de Físico-Química, Instituto de Química, Universidade Federal do Rio de Janeiro, Av. Athos da Silveira Ramos 149, A412, Rio de Janeiro, RJ 21941-909, Brazil tions, SBQT was a unique opportunity to get in touch with high-level science and to foster new collaborations. Moreover, given that over half of the total participants were undergraduate and graduate students, the Symposium was a unique and motivating opportunity for them to meet and discuss their research work with senior scientists of the area.

We also paid a tribute, in a special session, to Ricardo de Carvalho Ferreira, from the Federal University of Pernambuco, one of the Brazilian pioneers in the field of theoretical chemistry, who had just passed away.

We gratefully acknowledge the financial support to the 17th SBQT given by several agencies and sponsors. Among them, Fundação Carlos Chagas de Amparo à Pesquisa do Estado do Rio de Janeiro (FAPERJ), Coordenação de Aperfeiçoamento de Pessoal Nível Superior (CAPES), 16th Brazilian Symposium of Theoretical Chemistry (SBQT 2011) and Conselho Nacional de Desenvolvimento Científico e Tecnológico (CNPq).

Last, but not least, we gratefully thank Prof. Timothy Clark, Editor-in-Chief of Journal of Molecular Modeling, for embracing the idea of this Topical Issue, and the Journal Staff and the referees for their invaluable work. 